\title{
ANALISIS PENGARUH PENGGUNAAN AVR (AUTOMATIC VOLTAGE REGULATOR) TERHADAP SISTEM EKSITASI GENERATOR PADA BTG 1 (BOILER TURBIN GENERATOR) PT. SEMEN TONASA
}

\begin{abstract}
Andareas Pangkung ${ }^{1}$, Marhatang ${ }^{1}$, Citri Novianti Irlan², Ummul Fasiha ${ }^{2}$
Abstrak: Generator sinkron bekerja dengan mengubah energi mekanis menjadi energi listrik tiga fasa. Tegangan keluaran generator harus konstan. Namun, pada kenyataannya tegangan yang dihasilkan generator akan berubah akibat perubahan beban. Untuk menjaga agar tegangan tetap konstan pada tegangan nominalnya, maka dibutuhkan alat yang disebut AVR (Automatic Voltage Regulator). AVR ini bekerja dengan mengatur arus eksitasi agar nilai tegangan keluaran generator konstan. Hal itu sangat penting dalam menjaga tingkat stabilitas generator. Penelitian ini bertujuan untuk menganalisis penggunaan AVR pada sistem eksitasi generator. Dengan metode penelitian, mengukur parameter pada sistem eksitasi hingga tegangan keluaran generator. Kemudian dari data-data yang diperoleh, dapat dianalisis perfoma AVR kedua generator sehingga diketahui stabilitas generator pada setiap unitnya. Hasil penelitian menunjukkan bahwa AVR pada generator 2 bekerja lebih optimal dibandingkan dengan AVR pada generator 1. Ditunjukkan dengan regulasi tegangan pada generator 2 lebih rendah $(0,279 \%)$ dibandingkan regulasi tegangan pada generator $1(0,385 \%)$. Hal ini dikarenakan AVR generator 2 menggunakan AVR baru dengan tipe PRISMIC A3100 sedangkan AVR generator 1 tipe Unitrol F ABB memiliki usia pemakaian yang lama sehingga daya gunanya pun menurun.
\end{abstract}

Kata Kunci: AVR generator, Generator Sinkron, dan Sistem Eksitasi,

\section{PENDAHULUAN}

Seiring dengan pertumbuhan ekonomi dan tingkat populasi penduduk di Indonesia yang semakin tinggi maka permintaan akan energi listrik juga meningkat. Oleh karena itu berbagai upaya yang dilakukan oleh pemerintah agar dapat memenuhi kebutuhan listrik masyarakat. Selain dalam masyarakat, kebutuhan listrik juga sangat dibutuhkan dalam dunia perindustrian. Ada beberapa industri yang menggunakan pembangkit listrik tenaga uap salah satunya PLTU PT. Semen Tonasa atau biasa disebut dengan istilah BTG yaitu boiler, turbin, generator.

Pembangkit Listrik Tenaga Uap (PLTU) PT. Semen Tonasa berfungsi sebagai penghasil uap yang nantinya digunakan untuk menggerakkan turbin untuk menghasilkan listrik.Pembangkitan energi listrik dihasilkan oleh sebuah generator. Generator menghasilkan energi listrik karena terdapat arus eksitasi yang mengeksitasi rotor generator. Dimana sistem eksitasi pada generator merupakan sistem mengalirnya pasokan listrik arus searah sebagai penguatanpada generator listrik, sehingga menghasilkan energi listrik dan besar tegangan keluaran bergantung pada besarnya arus eksitasi. Namun selain memperhitungkan sistem eksitasi yang digunakan, sangat perlu diperhatikan stabilitas generator. Tegangan yang dihasilkan oleh generator harus konstan. Pada kenyataan, tegangan yang dihasilkan generator akan berubah akibat perubahan beban. Untuk menjaga agar tegangan tetap konstan dalam nilai yang diizinkan, maka dibutuhkan alat yang disebut AVR (Automatic Voltage Regulator)yang merupakan peralatan yang paling penting bagi generator, karena stabilitas generator bisa mempengaruhi stabilitas sistem pembangkit listrik secara umum yang dapat menunjang kehandalan suatu sistem pembangkitan.

\subsection{Prinsip Kerja Generator}

Prinsip dasar generator arus bolak-balik menggunakan Hukum Faraday yang menyatakan jika sebatang penghantar berada pada medan magnet yang berubah -ubah, maka pada penghantar tersebut akan terbentuk gaya gerak listrik. Pada kumparan rotor yang berfungsi sebagai pembangkit

\footnotetext{
${ }^{1}$ Staf Pengajar D4 Jurusan Teknik Mesin Politeknik Negeri Ujung Pandang

${ }^{2}$ Alumni Program D4 Jurusan Teknik Mesin Politeknik Negeri Ujung Pandang
} 
43 Andareas Pangkung, Marhatang, Citri Novianti Irlan, Ummul Fasiha. Analisis Pengaruh Penggunaan Avr (Automatic Voltage Regulator) Terhadap Sistem Eksitasi Generator Pada Btg 1 (Boiler Turbin Generator)

Pt. Semen Tonasa

kumparan medanmagnet yang terletak di antara kutub magnet utara dan selatan diputar oleh primemover, maka pada kumparan rotor akan timbul medan magnet atau fluks yang bersifat bolakbalik atau fluks putar. Fluks putar ini akan memotong-motong kumparan stator sehingga pada ujungujung kumparan stator timbul gaya geraklistrik karena pengaruh induksi dari fluks putar tersebut.

Gaya gerak listrik (GGL) yang timbul pada kumparan stator juga bersifat bolak-balik, atau berputar dengan kecepatan sinkron terhadap kecepatan putar rotor. Frekuensi elektris yang dihasilkan generator sinkron adalah sinkron dengan kecepatan putar generator. Rotor generator sinkron terdiri atas rangkaian elektromagnet dengan suplai arus DC. Medan magnet rotor bergerak pada arah putaran rotor. Oleh karena rotor berputar pada kecepatan yang sama dengan medan magnet, persamaan diatas juga menunjukkan hubungan antara kecepatan putar rotor dengan frekuensi listrik yang dihasilkan. Agar daya listrik dibangkitkan tetap pada frekuensi $50 \mathrm{~Hz}$ atau $60 \mathrm{~Hz}$, maka generator harus berputar pada kecepatan tetap dengan jumlah kutub mesin yang telah ditentukan. Sebagai contoh untuk membangkitkan $60 \mathrm{~Hz}$ pada mesin dua kutub, rotor arus berputar dengan kecepatan $3600 \mathrm{rpm}$. Untuk membangkitkan daya $50 \mathrm{~Hz}$ pada mesin empat kutub, rotor harus berputar pada $1500 \mathrm{rpm}$.

\subsection{Sistem Eksitasi Dan AVR Generator}

Sistem eksitasi adalah sistem mengalirnya pasokan listrik DC sebagai penguatan pada generator listrik, sehingga menghasilkan tenaga listrik dan besar tegangan output bergantung pada besarnya arus eksitasi. Perkembangan sistem eksitasi generator cenderung ke sistem eksitasi tanpa sikat, karena adanya sikat menimbulkan kesulitan, misalnya timbul loncatan api pada putaran tinggi dan daya tinggi pada generator arus searah yang menghasilkan arus penguat. Untuk menghilangkan sikat digunakan rotating diode. Macam-macam sistem eksitasi:

1.2.1. Sistem eksitasi dengan sikat (brush excitation)

Sistem eksitasi menggunakan sikat, sumber tenaga listrik berasal dari sumber listrik yang berasal dari generator arus searah (DC) atau generator arus bolak balik (AC) yang disearahkan terlebih dahulu dengan menggunakan rectifier. Dalam lemari penyearah, tegangan listrik arus bolak balik diubah atau disearahkan menjadi tegangan arus searah untuk mengontrol kumparan medanexciter utama (main exciter). Untuk mengalirkan arus eksitasi dari main eksiter ke rotor generator menggunakan slip ring dan sikat arang, demikian juga penyaluran arus yang berasal dari pilot exciter ke main exciter.

\subsubsection{Sistem eksitasi tanpa sikat (brushless excitation)}

Pada brushless excitation atau eksitasi tanpa sikat,sistem tersebut menyalurkan arus eksitasi ke rotor generator utama maupun untuk eksitasi eksiter tidak melalui media sikat. Seperti pada gambar berikut.

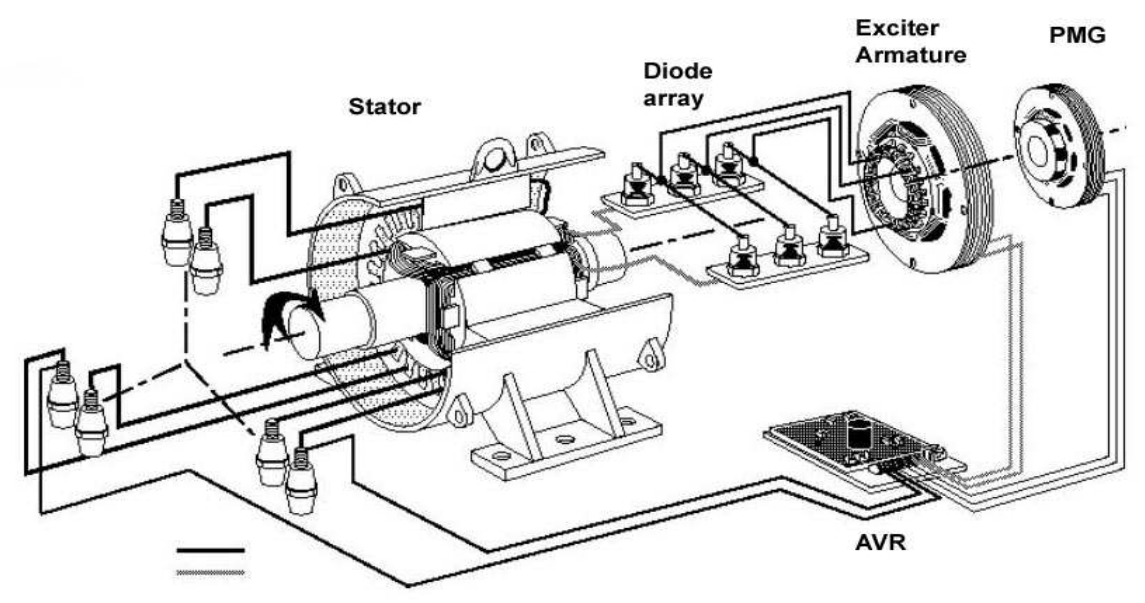

Gambar 1 Brushless Excitation 
Pada gambar 1 dapat dilihat bahwa untuk eksitasi generator disuplai dari generator AC eksiter dengan melalui penyearah (rotating diode) yang terpasang pada poros, sehingga arus eksitasi langsung terhubung dengan rotor generator. Kemudian untuk eksitasi eksiter disuplai dari pilot eksiter dengan kemagnetan tetap atau disebut dengan PMG.

Output dari PMG tersebut adalah single phasa atau tiga phasa. Kemudian melalui penyearah pada modul regulator (AVR), arus eksitasi eksiter diatur besar kecilnya, sehingga dengan mengatur eksitasi maka tegangan keluaran generator utama akan mengalami perubahan secara langsung.Pada sistem eksitasi tanpa sikat, permasalahan timbul apabila terjadi gangguan hubung singkat atau gangguan hubung tanah di rotor, serta apabila ada beberapa dioda yang mengalami kerusakan, maka solusinya adalah melakukan penggantian dimana Unit harus dimatikan terlebih dahulu, kejadian ini dapat menimbulkan distorsi medan magnet pada generator yang selanjutnya menimbulkangetaran (vibrasi) berlebihan pada unit pembangkit.

\subsection{AVR (Automatic Voltage Regulator)}

Untuk menghasilkan kualitas daya listrik yang baik, salah satu faktor yang harus dipenuhi adalah tegangan yang dihasilkan generator harus konstan. Pada kenyataan, tegangan yang dihasilkan generator akan berubah akibat perubahan beban. Bila beban pada generator sinkron bertambah maka tegangan yang dihasilkan akan menurun, dan sebaliknya tegangan akan naik apabila beban berkurang. Dengan demikian perlu suatu alat penstabil tegangan dinamakan Automatic Voltage Regulator (AVR).Sistem pengoperasian Unit AVR (Automatic Voltage Regulator) berfungsi untuk menjaga agar tegangan generator tetap konstan dengan kata lain generator akan tetap mengeluarkan tegangan yang selalu stabil tidak terpengaruh pada perubahan beban yang selalu berubah-ubah, dikarenakan beban sangat mempengaruhi tegangan output generator.

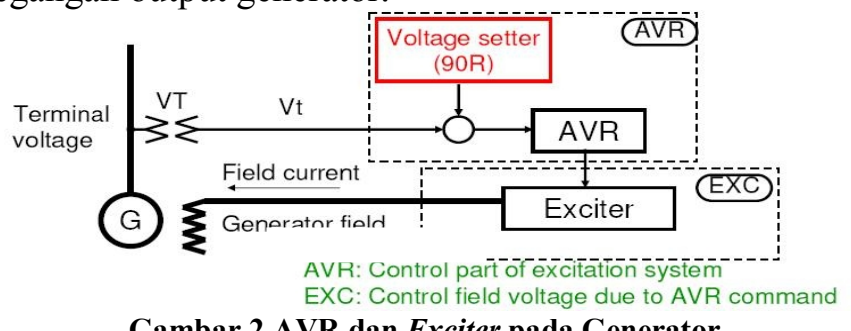

\section{METODE PENELITIAN}

\subsection{Objek Penelitian}

Objek dalam penelitian ini yaitu generator pada Unit 1 dan 2 BTG 1 PT.Semen Tonasa, dimana generator tersebut merupakan generator sinkron. Dalam setiap unit generator mempunyai sistem eksitasi yang sangat berpengaruh pada tegangan keluaran generator. Sistem eksitasi ini dikontrol oleh AVR untuk menjaga tegangan generator tetap konstan.

\subsection{Teknik Pengumpulan Data}

Adapun teknik pengumpulan data dilakukan untuk memperoleh data-data yang merupakan gambaran kenyataan yang terjadi di BTG 1 PT.Semen Tonasa dengan cara observasi yaitu dengan melakukan pengamatan secara langsung pada berbagai kegiatan pengoperasian sistem yang ada pada ECR (Electrical Control Room). Selain itu, metode observasi langsung ini jugadilakukan pada komponen-komponen unit generator BTG 1 PT. Semen Tonasa seperti, pada AVR dan Sistem Eksitasi Generator. Observasi dilakukan dengan tujuan untuk dapat mengidentifikasi masalah yang terjadi, kemudian melakukan pengumpulan data yang dilakukan secara real time berdasarkandata record melalui sistem pengontrolan yang ada pada ECR (Electrical Control Room).

\subsection{Metode Analisis Data}


45 Andareas Pangkung, Marhatang, Citri Novianti Irlan, Ummul Fasiha. Analisis Pengaruh Penggunaan Avr (Automatic Voltage Regulator) Terhadap Sistem Eksitasi Generator Pada Btg 1 (Boiler Turbin Generator) Pt. Semen Tonasa

Setelah memperoleh data-data yang diperlukan maka dapat dianalisis beberapa parameter menggunakan persamaan-persamaan berdasarkan teori yang ada pada tinjauan pustaka. Sehingga hasil analisis data dapat menggambarkan karakteristik generator yang akan menunjukkan optimasi penggunaan AVR terhadap sistem eksitasi generator.

\section{HASIL PENELITIAN}

\begin{tabular}{|c|c|c|c|c|c|c|c|c|c|c|}
\hline \multicolumn{10}{|c|}{ Tabel 1. Pengamatan Data Generator 1 (ACC 2) } \\
\cline { 1 - 10 } Waktu & $\mathrm{V}_{\mathrm{g}}$ & $\mathrm{I}_{\mathrm{g}}$ & $\mathrm{P}$ & $\mathrm{Q}$ & $\mathrm{P}_{\text {tot }}$ & $\mathrm{I}_{\mathrm{exc}}$ & $\mathrm{V}_{\text {exc }}$ & $\mathrm{S}$ & \multirow{2}{*}{ Cos $\varphi$} & \multirow{2}{*}{ Regulasi Tegangan $(\%)$} \\
\hline (WITA) & $(\mathrm{V})$ & $(\mathrm{A})$ & $(\mathrm{kW})$ & $(\mathrm{kVar})$ & $(\mathrm{kW})$ & $(\mathrm{A})$ & $(\mathrm{V})$ & $(\mathrm{kVA})$ & & 0,032 \\
\hline $09: 00$ & 6.298 & 2.064 & 18.370 & 12.000 & 36.250 & 4,5 & 25 & $22.515,05$ & 0,816 & 0,159 \\
\hline $10: 00$ & 6.290 & 2.003 & 18.060 & 12.000 & 35.260 & 4,5 & 25 & $21.821,88$ & 0,828 & 0,271 \\
\hline $11: 00$ & 6.283 & 1.963 & 17.950 & 11.000 & 34.100 & 4 & 25 & $21.362,3$ & 0,840 & 0,462 \\
\hline $12: 00$ & 6.271 & 1.717 & 15.630 & 10.000 & 29.500 & 4 & 25 & $18.649,52$ & 0,838 & 0,527 \\
\hline $13: 00$ & 6.267 & 1.697 & 15.380 & 10.000 & 29.480 & 3,5 & 25 & $18.420,53$ & 0,835 & 0,575 \\
\hline $14: 00$ & 6.264 & 1.657 & 15.370 & 10.000 & 29.500 & 3,5 & 25 & $17.977,73$ & 0,855 & 0,591 \\
\hline $15: 00$ & 6.263 & 1.711 & 15.354 & 10.000 & 30.420 & 3,5 & 25 & $18.560,64$ & 0,827 & 0,719 \\
\hline $16: 00$ & 6.255 & 1.687 & 15.352 & 10.000 & 29.760 & 3,5 & 25 & $18.276,92$ & 0,840 & 0,417 \\
\hline
\end{tabular}

Tabel 2. Pengamatan Data Generator 2 (ACC 3)

\begin{tabular}{|c|c|c|c|c|c|c|c|c|c|c|}
\hline $\begin{array}{c}\text { Waktu } \\
(\text { WITA })\end{array}$ & $\begin{array}{c}\mathrm{V}_{\mathrm{g}} \\
(\mathrm{V})\end{array}$ & $\begin{array}{c}\mathrm{I}_{\mathrm{g}} \\
(\mathrm{A})\end{array}$ & $\begin{array}{c}\mathrm{P} \\
(\mathrm{kW})\end{array}$ & $\begin{array}{c}\mathrm{Q} \\
\mathrm{kVar})\end{array}$ & $\begin{array}{c}\mathrm{P}_{\text {tot }} \\
(\mathrm{kW})\end{array}$ & $\begin{array}{c}\mathrm{I}_{\text {exc }} \\
(\mathrm{A})\end{array}$ & $\begin{array}{c}\mathrm{V}_{\text {exc }} \\
(\mathrm{V})\end{array}$ & $\begin{array}{c}\mathrm{S} \\
(\mathrm{kVA})\end{array}$ & Cos $\varphi$ & Regulasi Tegangan (\%) \\
\hline \hline $09: 00$ & 6.295 & 1.986 & 17.980 & 12.500 & 36.250 & 4 & 25 & $21.653,87$ & 0,830 & 0,079 \\
\hline $10: 00$ & 6.288 & 1.924 & 17.210 & 12.000 & 35.260 & 3,5 & 25 & $20.954,54$ & 0,821 & 0,191 \\
\hline $11: 00$ & 6.278 & 1.818 & 16.250 & 12.000 & 34.100 & 3,5 & 25 & $19.768,6$ & 0,822 & 0,350 \\
\hline $12: 00$ & 6.271 & 1.691 & 15.160 & 12.000 & 29.500 & 3 & 25 & $18.367,12$ & 0,825 & 0,462 \\
\hline $13: 00$ & 6.268 & 1.660 & 15.150 & 13.000 & 29.480 & 3 & 25 & $18.021,78$ & 0,841 & 0,511 \\
\hline $14: 00$ & 6.267 & 1.657 & 15.130 & 12.000 & 29.500 & 3 & 25 & $17.986,34$ & 0,841 & 0,527 \\
\hline $15: 00$ & 6.264 & 1.656 & 15.130 & 11.500 & 30.420 & 3 & 25 & $17.966,88$ & 0,842 & 0,575 \\
\hline $16: 00$ & 6.260 & 1.654 & 15.110 & 11.500 & 29.760 & 3 & 25 & $17.933,72$ & 0,843 & 0,639 \\
\hline
\end{tabular}

\section{I.1. Analisis Data}

1. Generator 1

Berdasarkan data pada tabel 1 dapat diketahui :

Jam 09.00 WITA

$\begin{array}{ll}\text { Tegangan generator }\left(\mathrm{V}_{\mathrm{g}}\right) & =6,298 \mathrm{kV} \\ \text { Arus generator }\left(\mathrm{I}_{\mathrm{g}}\right) & =2.064 \mathrm{~A} \\ \text { Daya }(\mathrm{P}) & =18.370 \mathrm{~kW}\end{array}$

Tegangan nominal generator $\left(\mathrm{E}_{0}\right)=6,3 \mathrm{kV}$

1) Daya Semu

Line to line/3 fasa

$\mathrm{S}=\sqrt{3}$.V.I

$\mathrm{S}=\sqrt{3} \cdot 6,298 \mathrm{kV} .2064 \mathrm{~A}$

$=22515,05 \mathrm{kVA}$

2) Faktor Daya

$\operatorname{Cos} \varphi=\frac{P}{S}$

DOI : $\underline{\text { http://dx.doi.org/10.31963/sinergi.v16i1.1201 }}$ 
$\operatorname{Cos} \varphi=\frac{1}{2 \quad, 0}$

$$
=0,816
$$

3) Regulasi Tegangan

$\%$ Regulasi Tegangan $=\frac{E-V}{V} \times 100 \%$

$$
\begin{aligned}
& =\frac{6,3-6,2}{6,2} \times 100 \% \\
& =0,032 \%
\end{aligned}
$$

2. Generator 2

Berdasarkan data pada tabel 1 dapat diketahui :

Jam 09.00 WITA

Tegangan generator $\left(\mathrm{V}_{\mathrm{g}}\right) \quad=6,295 \mathrm{kV}$

Arus generator $\left(\mathrm{I}_{\mathrm{g}}\right) \quad=1.986 \mathrm{~A}$

Daya (P) $\quad=17.980 \mathrm{~kW}$

Tegangan nominal generator $\left(\mathrm{E}_{0}\right)=6,3 \mathrm{kV}$

1. Daya Semu

Line to line/3 fasa

$\mathrm{S}=\sqrt{3}$.V.I

$\mathrm{S}=\sqrt{3} \cdot 6,295 \mathrm{kV} .1986 \mathrm{~A}$

$=21653,9 \mathrm{kVA}$

2. FaktorDaya

$\operatorname{Cos} \varphi=\frac{P}{S}$

$\operatorname{Cos} \varphi=\frac{1}{2,9}$

$=0,830$

3. RegulasiTegangan

$\%$ Regulasi Tegangan $=\frac{E-V}{V} \times 100 \%$

$$
=\frac{6,3-6,2}{6,2} \times 100 \%
$$

$=0,385 \%$

\subsection{Analisis Grafik}

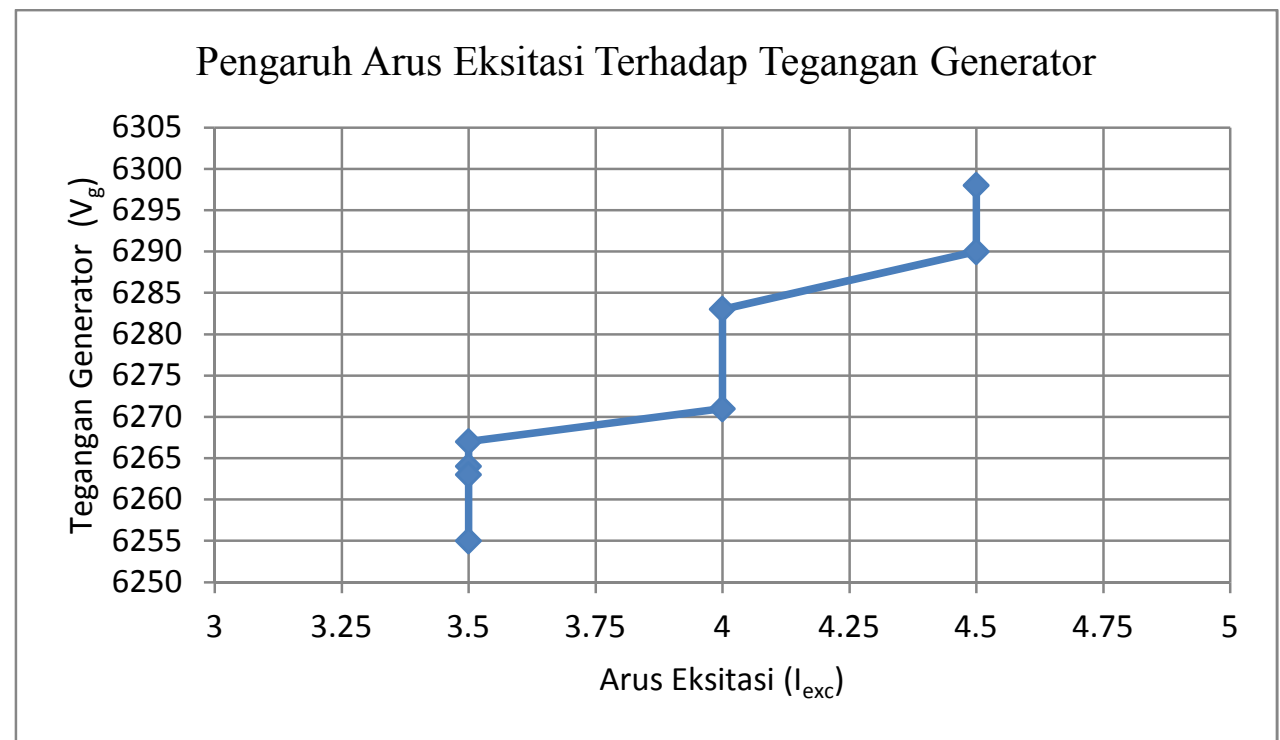

Gambar 3. Hubungan antara arus eksitasi terhadap tegangan pada generator 1 
47 Andareas Pangkung, Marhatang, Citri Novianti Irlan, Ummul Fasiha. Analisis Pengaruh Penggunaan Avr (Automatic Voltage Regulator) Terhadap Sistem Eksitasi Generator Pada Btg 1 (Boiler Turbin Generator) Pt. Semen Tonasa

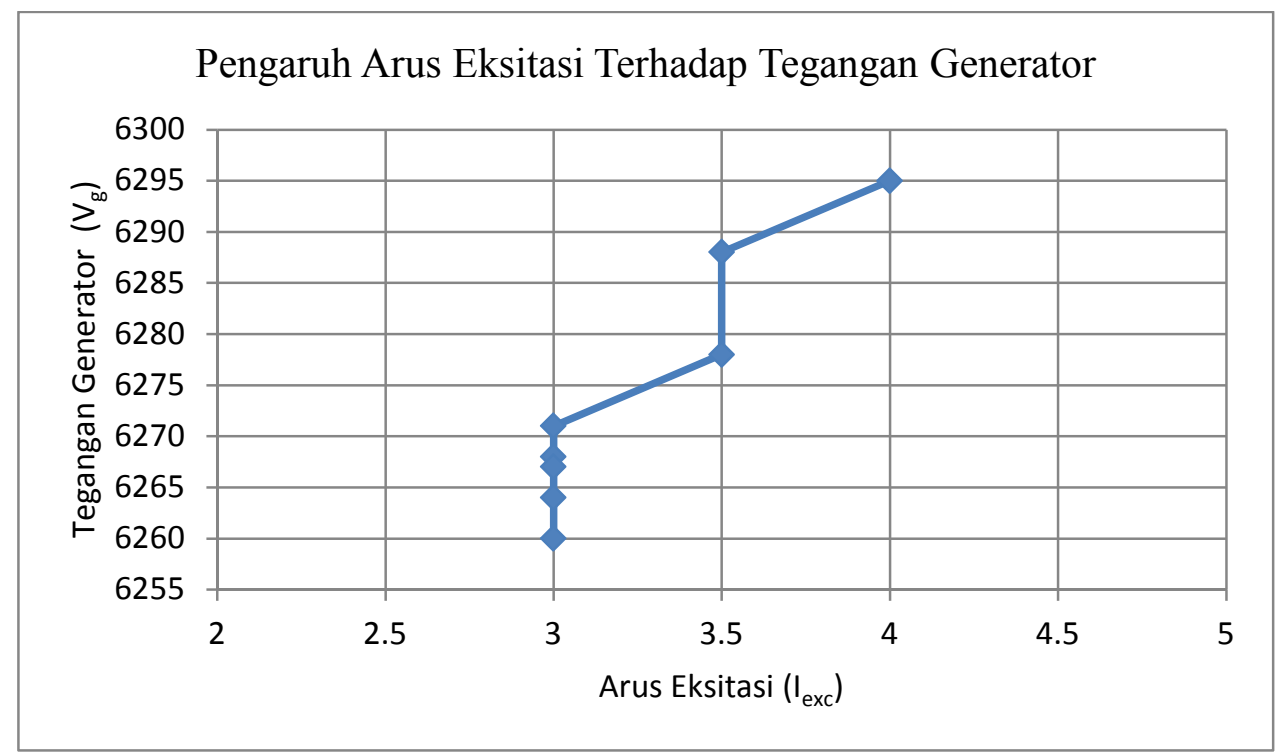

Gambar 4. Hubungan antara arus eksitasi terhadap tegangan pada generator 2

Pada gambar 3 dan 4 terlihat bahwa semakin kecil arus eksitasi maka semakin kecil pula tegangan generatornya. Seperti pada keadaan awal tegangan generator 1 yaitu $6,298 \mathrm{kV}$ dan arus eksitasi 4,5 A, kemudian pada keadaan akhir tegangan generator 1 turun $6,255 \mathrm{kV}$ yang dikarenakan arus eksitasinya menurun menjadi 3,5 A. Begitupun pada generator 2 keadaan awal tegangan $6,295 \mathrm{kV}$ dan arus 4 A turun menjadi $6,260 \mathrm{kV}$ dan $3 \mathrm{~A}$. Hal ini disebabkan karena terjadinya fluktuasi beban, sehingga tegangan generator berubah-ubah. Dan apabila arus eksitasi dinaikkan maka tegangan generator juga meningkat bertujuan agar tegangan menjadi konstan pada tegangan nominalnya.

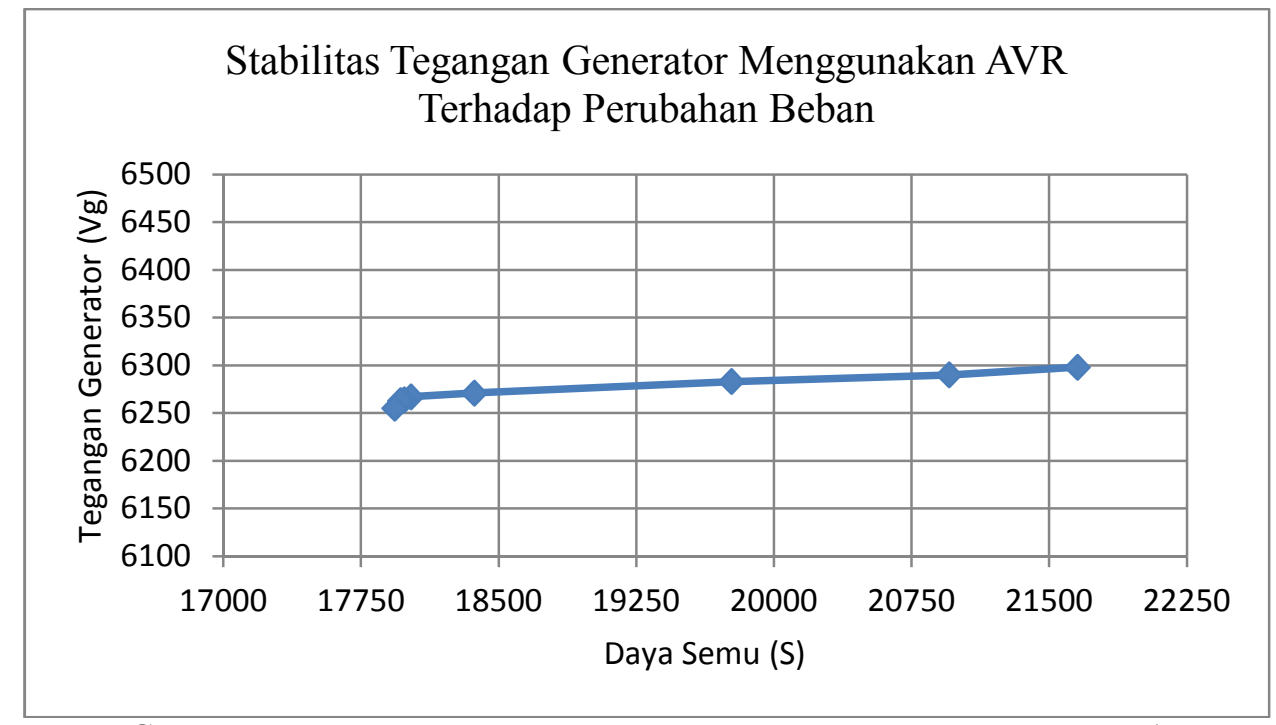

Gambar 5. Hubungan antara tegangan terhadap daya semu pada generator 1 


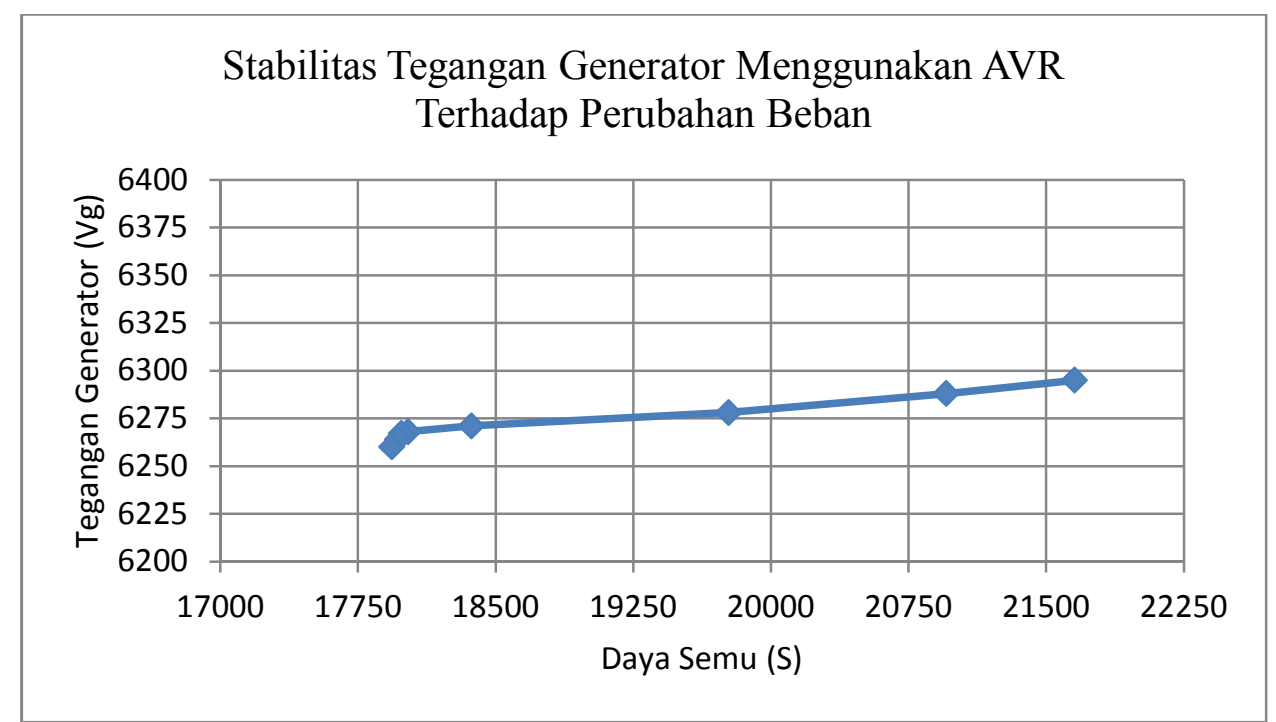

Gambar 6. Hubungan antara tegangan terhadap daya semu pada generator 2

Pada gambar 5 dan 6 terlihat bahwa tegangan generator mendekati nilai konstan yaitu $6,3 \mathrm{kV}$, meskipun terjadinya perubahan beban yang sangat tinggi. Seperti keadaan awal tegangan dan daya semu kedua generator menurun secara signifikan. Dimana nilai tegangan awal generator 1 yaitu 6,298 $\mathrm{kV}$ dan daya semunya $22515,05 \mathrm{kVA}$ turun pada keadaan akhir tegangan menjadi $6,255 \mathrm{kV}$ dan daya semu 18276,92 kVA. Begitupun pada generator 2 dari tegangan 6,298 $\mathrm{kV}$ dan daya semu 21653,9 $\mathrm{kVA}$ turun menjadi $6,260 \mathrm{kV}$ dan daya semu $17933,7 \mathrm{kVA}$.

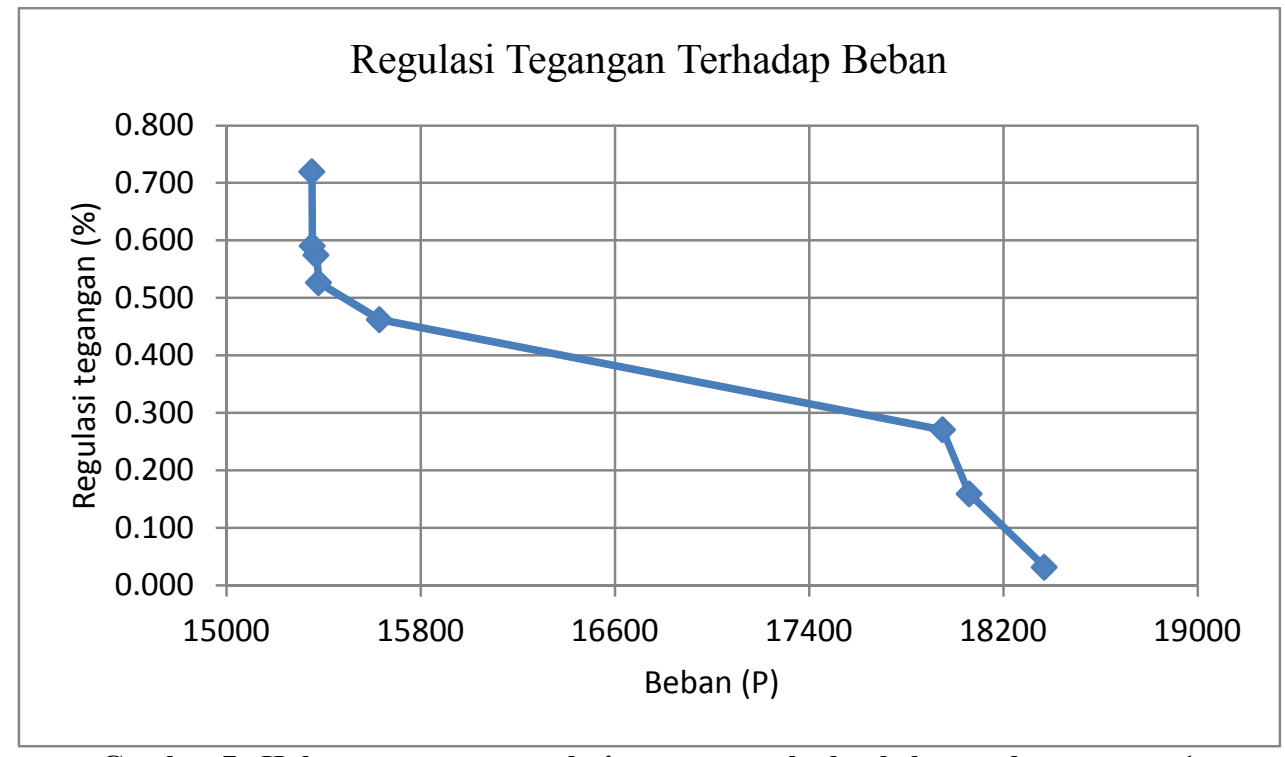

Gambar 7. Hubungan antara regulasi tegangan terhadap beban pada generator 1 
49 Andareas Pangkung, Marhatang, Citri Novianti Irlan, Ummul Fasiha. Analisis Pengaruh Penggunaan Avr (Automatic Voltage Regulator) Terhadap Sistem Eksitasi Generator Pada Btg 1 (Boiler Turbin Generator) Pt. Semen Tonasa

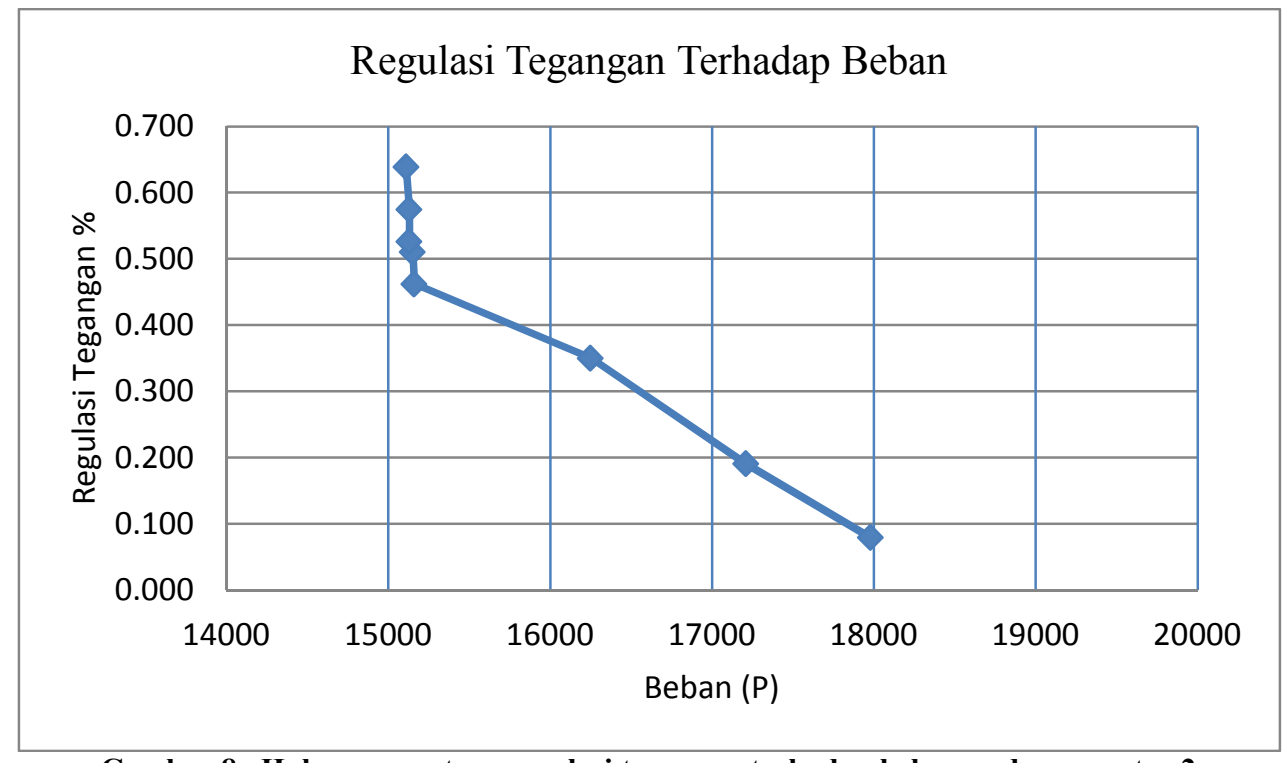

Gambar 8. Hubungan antara regulasi tegangan terhadap beban pada generator 2

Pada gambar 7 dan 8 terlihat bahwa perubahan beban berpengaruh juga pada regulasi tegangan generator. Dimana regulasi tegangan meningkat dalam keadaan beban yang semakin menurun. Regulasi tegangan yang meningkat disebabkan oleh tegangan yang semakin menurun. Hal ini dikarenakan arus eksitasi juga menurun pada setiap generator, sehingga tegangan generator pada beban yang rendah juga semakin menurun. Ditunjukkan pada keadaan awal regulasi tegangan generator 1 yaitu $0,032 \%$ dengan beban $18370 \mathrm{~kW}$ kemudian pada keadaan akhir regulasi tegangan meningkat menjadi $0,719 \%$ dengan beban yang turun $15352 \mathrm{~kW}$. Begitupun generator 2, keadaan awal regulasi tegangan yaitu 0,079 \% dengan beban $17980 \mathrm{~kW}$ kemudian pada keadaan akhir regulasi tegangan $0,639 \%$ dengan beban turun $15110 \mathrm{~kW}$.

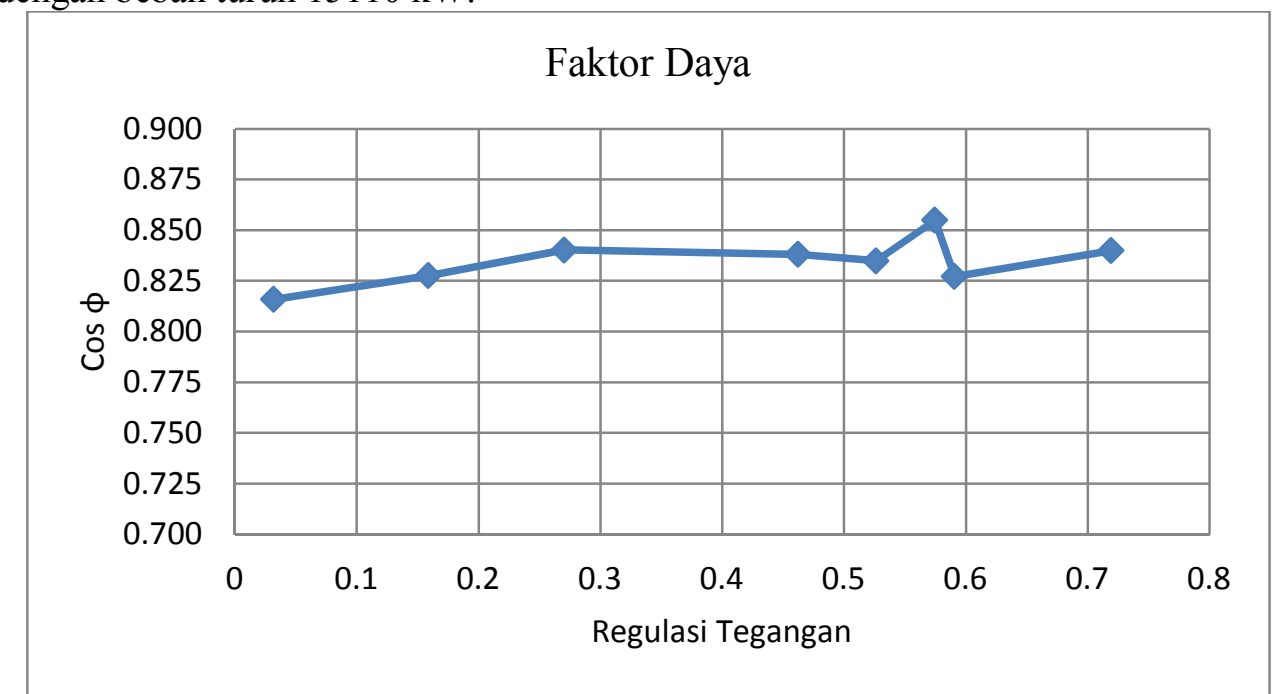

Gambar 9. Hubungan antara faktor daya terhadap regulasi tegangan generator 1 


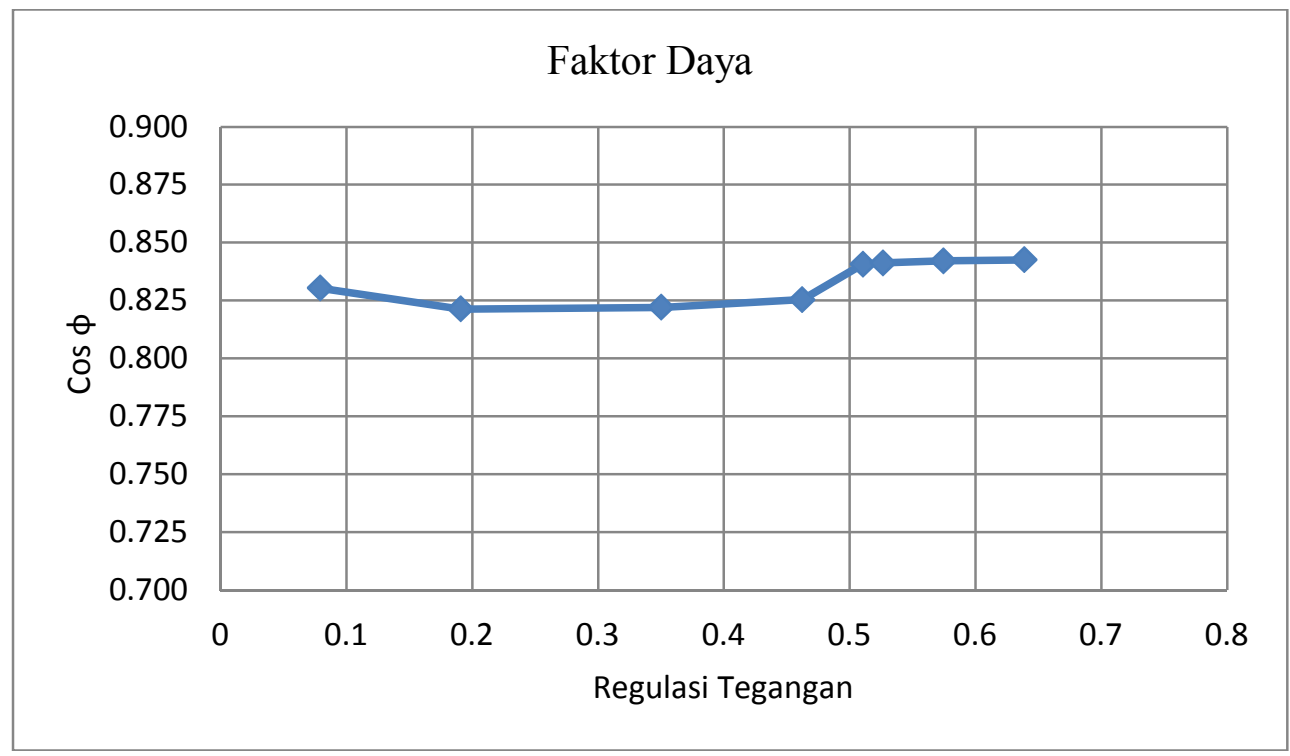

Gambar 10. Hubungan antara faktor daya terhadap regulasi tegangan generator 2

Pada gambar 9 dan 10 terlihat bahwa nilai $\cos \varphi$ kedua generator pada kisaran $+0,8$. Dapat dilihat pada keadaan awal generator 1 dan 2 sampai keadaan akhir nilai $\cos \varphi$ cenderung konstan pada nilai 0,8 sementara regulasi tegangan berfluktuatif. Persentase regulasi tegangan dibawah 1\% menunjukkan perfoma AVR generator yang bekerja optimal, sehingga nilai $\cos \varphi$ juga terjaga pada nilai $\pm 0,8$.

\section{KESIMPULAN}

Dari hasil dan pembahasan diatas dapat disimpulkan bahwa:

1. Kedua generator pada BTG 1 PT. Semen Tonasa menggunakan sistem eksitasi brushless. Sistem tersebut menyalurkan arus eksitasi ke rotor generator utama dengan eksitasi eksiter tidak melalui media sikat. Eksitasi disuplai dari generator AC eksiter dengan melalui rotating diode pada poros, sehingga arus eksitasi langsung terhubung dengan rotor generator. Untuk eksitasi exicer di suplai dari PMG (permanent magnet generator).

2. AVR generator dapat bekerja optimal pada beban tertinggi yaitu $18370 \mathrm{~kW}$. Dimana tegangan generator $6,298 \mathrm{kV}$ mendekati tegangan nominalnya $6,3 \mathrm{kV}$. Walaupun diberikan beban tinggi namun presentase regulasi tegangan sangat kecil yaitu $0,032 \%$. Hal ini dikarenakan AVR bekerja dengan menaikkan arus eksitasi 4,5 A sehingga tegangan generator hampir konstan.

3. Generator 2 memiliki tingkat stabilitas generator lebih tinggi. Hal ini dapat dilihat pada regulasi tegangan generator 2 yang selalu lebih kecil dibanding dengan regulasi tegangan generator 1. Dapat pula ditunjukkan pada persentase perubahan tegangan generator 1 dari keadaan terrendah sampai tertinggi yaitu $0,68 \%$. Sementara pada persentase perubahan tegangan generator 2 hanya sampai $0,55 \%$.

\section{DAFTAR PUSTAKA}

Ariani Dwi, Wisna. dkk. 2012. Sistem Penguatan Medan Magnet (Brushless E Excitation System) dan Pemeliharaannya Pada Generator Unit 2 PLTG Cilacap.(Online).(http://www.elektro.undip.ac.id/el kpta/wpcontent/uploads/2012/05/L2F00 9027_MKP.pdf, diakses pada tanggal 5 Maret 2015). 
51 Andareas Pangkung, Marhatang, Citri Novianti Irlan, Ummul Fasiha. Analisis Pengaruh Penggunaan Avr (Automatic Voltage Regulator) Terhadap Sistem Eksitasi Generator Pada Btg 1 (Boiler Turbin Generator)

Pt. Semen Tonasa

Endriyanto. Perencanaan Optimal Sistem Control AVR (Automatic Voltage Regulator) Untuk Memperbaiki Kestabilan Tegangan Dengan Menggunakan Algoritma Genetic.Semarang :Universitasdiponegoro

Hage. 2009. Prinsip Kerja Generator Sinkron. (Online). (http://dunialistrik.blogspot.com/2009/04/prinsip-kerja-generator-sinkron.html, diakses pada tanggal 8 Maret 2015).

Hassan, dennis. dkk. 2014. Sistem Eksitasi Generator Dengan Menggunakan Avr (Automatic Voltage Regulator) Di Pltu Pacitan, Semarang: Universitas Diponegoro.

Imam Fauzi, Muhammad. dkk. 2010. Sistem Penguatan Tanpa Sikat (Brushless Excitation System) pada generator PLTU unit 3 Tambak Lorok Semarang, (Online).(http://eltek.polinema.ac.id/public/upload/file/3.Imron Eksitasi.pdf, diakses pada 5 Maret 2015).

Laksono, Heru Dibyo. dkk. 2015. Analisa Performansi Tanggapan Tegangan Sistem Eksitasi Generator Terhadap Perubahan Parameter. Jurnal, Vol 4, No.1.

Marsudi, Djiteng. 2005. Pembangkitan Energi Listrik. Jakarta: Erlangga.

Pangkung, Andareas., M.T. Ir. 2010. Diktat Mesin Listrik 1. Makassar : Politeknik Negeri Ujung pandang.

Sumanto, MA, Drs. 1992. Mesin Sinkron. Yogyakarta : Andi Offset. 